\title{
Kepemimpinan Spiritual dan Reward Terhadap Kinerja Pegawai Melalui Kualitas Kehidupan Kerja Dan Kepuasan Kerja sebagai Variabel Intervening
}

\author{
Padmayuda Tri Rachmawan", Dwi Nita Aryani \\ Sekolah Tinggi Ilmu Ekonomi Malangkucecwara \\ Jl. Terusan Candi Kalasan, Blimbing, Mojolangu, Kota Malang, Jawa Timur, Indonesia \\ *Koresponden: 45yuda@gmail.com
}

\section{Artikel Info \\ Received: \\ 14 Februari 2020 \\ Revised: \\ 28 September 2020 \\ Accepted: \\ 30 Oktober 2020}

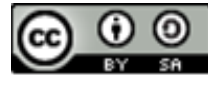

Published by Jurnal Ilmiah Manajemen dan Bisnis, Indonesia | Copyright (C) 2020 by the Author(s) | This is an open access article distributed under the Creative Commons Attribution License http://creativecommons.org/licenses /by/4.0), which permitsunrestricted use distribution, and reproduction in any medium, provided the original work is properly cited.

\begin{abstract}
ABSTRAK
Tujuan dari penelitian adalah menganalisis pengaruh kepemimpinan spiritual dan reward terhadap kinerja pegawai melalui kualitas kehidupan kerja dan kepuasan kerja.. Objek penelitian adalah pegawai Dinas Perhubungan Kabupaten Pasuruan. Data diperoleh dari penyebaran kuesioner kepada semua pegawai yang berjumlah 86 orang. Data diuji dengan bantuan SmartPLS. Hasil penelitian membuktikan kepemimpinan spiritual tidak dapat mempengaruhi kinerja pegawai secara langsung; reward tidak berpengaruh terhadap kinerja pegawai; kualitas kehidupan kerja tidak memediasi pengaruh kepemimpinan spiritual terhadap kinerja pegawai; kualitas kehidupan kerja tidak mampu menjadi mediator dalam pengaruh reward terhadap kinerja; kepemimpinan spiritual tidak berpengaruh terhadap kinerja pegawai mesikupun dimediasi kualitas kehidupan kerja; terdapat pengaruh tidak langsung antara reward terhadap kinerja pegawai melalui mediasi kepuasan kerja; Kualitas kehidupan kerja tidak berpengaruh terhadap kinerja pegawai; Kepuasan kerja berpengaruh positif signifikan terhadap kinerja pegawai. Hasil penelitian ini memiliki implikasi yang baik pada praktik dan menambah literatur tentang pengaruh kepemimpinan spiritual dan reward terhadap kinerja. Hasil penelitian diharapkan dapat memberikan informasi yang dapat digunakan sebagai pedoman bagi Kantor Dinas Perhubungan Pasuruan untuk meningkatkan kepuasan dan kinerja karyawan.
\end{abstract}

Kata Kunci: Kepemimpinan spiritual, kepuasan, kinerja, kualitas kehidupan kerja, reward

\section{Spiritual Leadership and Reward on Employee Performance Through Quality Of Work Life and Job Satisfaction as Intervening Variables}

\begin{abstract}
The purpose of this study is to analyze the influence of spiritual leadership and reward toward employee performance with quality of work life and job satisfaction as a mediating variable. The object of research in this study is Pasuruan Regency Transportation Office. Data analysis uses the Partial Least Square method with the software of SmartPLS. Data is collected by distributing questionnaire to all 86 staff as the respondents. The results show Spiritual leadership does not affect employee performance; reward has no affect on employee performance; Spiritual leadership does not have an affect on employee performance if mediated by the quality of work life; Reward cannot influence employee performance through the quality of work life as a mediating variable; Spiritual leadership does not have an effect on employee performance which is mediated by quality of work life; there is a significant indirect effect of reward on employee performance through job satisfaction as the mediating variable; The quality of work life has insignificant effect on employee performance; Job satisfaction has a positive and significant effect on employee performance. The results give significant implications on real life practice and literature on the influence of spiritual leadership and reward on performance. This research provides information that can be used as a guideline for the Pasuruan Regency Trasnportation Office to elevate employee satisfaction and performance.
\end{abstract}

Keywords: Spiritual leadership, satisfaction, performance, quality of work life, reward

DOI: https://doi.org/10.30596/jimb.v21i2.5124

JEL CLASSIFICATION: O, O1, 015

Cara Sitasi :

Rachmawan, P. T., Aryani, D. N. (2020). Kepemimpinan Spiritual dan Reward Terhadap Kinerja Pegawai Melalui Kualitas Kehidupan Kerja Dan Kepuasan Kerja sebagai Variabel Intervening. Jurnal Ilmiah Manajemen dan Bisnis, 21(2), 136-148. https://doi.org/10.30596/jimb.v21i2.5124. 


\section{PENDAHULUAN}

Pemerintah sebagai organisasi sektor publik bertanggung jawab penuh dalam meningkatkan kesejahteraan masyarakat, melaksanakan pembangunan berkelanjutan dan berkeadilan sosial dalam menjalankan aspek-aspek fungsional dari pemerintahan secara efisien dan efektif sehingga dapat terwujud good governance. Dengan berkembangnya era reformasi, terdapat tuntutan untuk meningkatkan kinerja organisasi sektor publik agar mereka lebih berorientasi pada terwujudnya good public and corporate governance (Mardiasmo, 2009). Dengan demikian kepemimpinan menjadi faktor yang penting dalam mengendalikan jalannya organisasi atau perusahaan. Ditambahkan pernyataan dari Muslichah and Asrori (2018) yang menjelaskan bahwa gaya kepemimpinan akan mempengaruhi kepuasan karyawan. Melalui peran kepemimpinan yang didukung sumber daya yang dimiliki dapat mendukung organisasi untuk mencapai tujuannya. Agar organisasi pemerintah dapat mencapai tujuan diperlukan pegawai yang berkualitas, yang mampu bekerja dengan baik, produktif, terampil, kreatif, disiplin, tekun, loyal kepada pimpinan dan organisasi serta motivasi berusaha untuk memperoleh hasil kerja yang baik sehingga mampu meraih prestasi kerja. Selain itu, suatu organisasi pemerintah juga harus menghargai kinerja dan prestasi para pegawainya dengan memberikan sistem reward yang layak dan adil agar memuaskan dan meningkatkan kualaitas kehidupan kerja pegawainya.

Kepemimpinan di suatu organisasi pada umumnya masih memandang bahwa hakekat kepemimpinan adalah amanah dari manusia dan bukan suatu amanah dari Tuhan sekaligus dari manusia (Rida, 2018). Kepemimpinan akan berjalan efektif, disegani dan memiliki derajat yang tinggi bila seorang pemimpin memiliki 3 (tiga) kelebihan yakni kelebihan dalam bidang intelektual, jasmani (fisik) dan rohani (spiritual). Fry (2003) menjelaskan bahwa kualitas dari kepemimpinan spiritual ditunjukkan dari kejujuran, loyalitas, empati, rendah hati, integritas. Spiritualitas juga merupakan sumber motivasi yang kuat bagi para pengikut. Pemimpin yang menekankan nilai-nilai spiritual seringkali mampu membangkitkan motivasi terpendam dalam diri orang lain yang ternyata meningkatkan kepuasan dan produktivitas mereka di tempat kerja (Reave, 2005). Kepemimpinan spiritual menurut Fry (2003), Rafsanjani (2017), terdiri dari nilainilai, sikap, dan perilaku yang diperlukan untuk memotivasi diri sendiri dan orang lain. Kualitas kepemimpinan spiritual juga ditunjukkan dari ketekunan, mempunyai cita-cita tinggi, integritas, memberi harapan, empati, jujur, sabar, dapat dipercaya, loyal pada perusahaan dan rendah hati

Penelitian Wang, et al., (2019) dan Sureskiarti (2017) menyimpulkan adanya pengaruh kepemimpinan spiritual terhadap kinerja karyawan. Ditambahkan oleh Ghasemizad, Zadeh, and Bagheri (2012); Pio and Tampi (2018) yang menegaskan bahwa terdapat pengaruh langsung yang signifikan kepemimpinan spiritual terhadap kualitas kehidupan kerja, kepemimpinan spiritual terhadap kepuasan kerja, kualitas kehidupan kerja terhadap kepuasan kerja, kualitas kehidupan kerja terhadap komitmen terhadap perusahaan dan kinerja karyawan, kepuasan kerja terhadap kinerja karyawan. Namun sebaliknya, penelitian Kakiay (2017) justru menunjukkan bahwa kepemimpinan spiritual tidak berkontribusi terhadap kinerja guru.

Agar karyawan lebih semangat bekerja, perusahaan biasanya memberi penghargaan atau reward atas prestasi yang telah dicapai. Reward merupakan sesuatu yang diberikan kepada seseorang atau kelompok jika mereka dapat melakukan suatu keunggulan di bidang tertentu. Pemberian reward harus dilakukan oleh organisasi dengan layak dan adil kepada karyawan. Menurut Delamotte and Walker (1976) reward merupakan bagian penting untuk menentukan kualitas kerja. Ditambahkan pula oleh Mohd Yusuf (2013), reward juga sebagai penentu kinerja karyawan. Hasil penelitian Kusnoto (2011) tentang Pengaruh Reward terhadap Kinerja Guru di Madrasah Aliyah, Kabupaten Tegal menyimpulkan bahwa reward berpengaruh signifikan terhadap kinerja guru. Namun jika pemberian reward yang diberikan kepada pegawai yang berprestasi yang hanya berupa plakat, sertifikat dan piagam dirasakan pegawai belum 
menunjukkan keadilan dan tidak sesuai dengan tujuan untuk meningkatkan motivasi bekerja tidak akan berdampak pada peningkatan kinerja pegawai (Meyrina, 2017).

Organisasi harus mampu memberikan kepuasan bagi karyawannya jika ingin sumber daya manusianya bisa lebih produktif dalam mengerjakan tugasnya masing-masing yaitu dengan meningkatkan kepuasan kerja sehingga dapat mempertahankan karyawan agar nyaman di suatu organisasi. Chanana and Gupta (2016); Fadhil and Mayowan (2018) menyatakan bahwa kepuasan kerja memiliki pengaruh signifikan terhadap kinerja karyawan. Namun, pada penelitian lain didapatkan hasil yang berbeda dimana kepuasan kerja berpengaruh tidak signifikan terhadap kinerja karyawan (Fiqih, et al., 2016), (Hartono, 2018). Kepuasan kerja menurut Jalal and Zaheer (2017) tidak dapat menjadi mediator hubungan antara reward dengan kinerja karyawan.

Kualitas kehidupan kerja memiliki kaitan langsung dengan produktivitas, karena peningkatan kualitas kehidupan kerja pada akhirnya akan mengarah pada produktivitas dan kepuasan kerja yang lebih tinggi (Ghasemizad, 2013). Hal ini sejalan dengan Yvonne, Rahman, and Long (2014) yang menjelaskan pengaruh yang positif dan signifikan antara kepuasan kerja dengan kinerja. Hal ini didukung penelitian Chanana and Gupta (2016); Cross and Daniel (2020) yang menjelaskan bahwa kualitas kehidupan kerja dapat meningkatkan kinerja karyawan. Namun penelitian Ahmad, Ahmad, and Shah (2010) menunjukan hasil yang berbeda, dimana kepuasan kerja tidak mempengaruhi kinerja karyawan advertising di Pakistan.

Pemberian reward dapat memberikan kepuasan bagi pegawai serta penciptaan kualitas kehidupan kerja. Kualitas kehidupan kerja menjadi mediator dalam pengaruh kepemimpinan spiritual terhadap kinerja pegawai. Reward berpengaruh terhadap kinerja pegawai melalui kualitas kehidupan kerja. Kualitas kehidupan kerja dan kepuasan kerja berpengaruh terhadap kinerja pegawai.

Sesuai dengan masalah dan fenomena tersebut, maka peneliti menggunakan dasar teori kualitas kehidupan kerja Walton (1974); (Zin, 2004), yang menjelaskan bahwa karyawan menilai kualitas kehidupan kerja dari delapan aspek yaitu kompensasi yang memadai dan adil, lingkungan yang aman dan sehat; pengembangan kapasitas karyawan; pertumbuhan dan keamanan; hubungan baik dengan karyawan; hubungan baik antara supervisor dengan karyawan; konstitusionalisme (respek terhadap karyawan; kesempatan untuk menyampaikan pendapat dan berpartisipasi) serta keseimbangan antara kerja dengan kehidupan sosial lainnya.

Özpehlivan and Acar (2015) menjelaskan dimensi dari kepuasan kerja adalah keterampilan manajemen, rekan kerja, pekerjaan dan kondisi kerja, promosi, gaji dan lingkungan eksternal. Sedangkan dimensi kepuasan kerja menurut (Colquitt, et al., 2009), Luthans (2006) diukur dari pekerjaan yang diberikan merupakan tugas yang menarik; mendapat kesempatan untuk belajar dan bertanggung jawab; gaji; kesempatan untuk dipromosikan; pengawasan yang dilakukan oleh penyelia; teman kerja yang mendukung; serta kondisi lingkungan kerja. Dengan adanya dukungan dimensi tersebut maka dapat meningkatkan kepuasan kerja karyawan.

Jika semua variabel tersebut diterima oleh karyawan, maka akan meningkatkan kinerja karyawan yang diukur dengan produktivitas yang diterjemahkan menjadi kuantitas output, kualitas keluaran, ketepatan waktu keluaran, keberadaan atau kehadiran di tempat kerja, moral di tempat kerja, efisiensi pekerjaan selesai dan efektivitas pekerjaan selesai (Mathis \& Jackson, 2010)

Dinas Perhubungan Kabupaten Pasuruan merupakan salah satu bagian penting dari Pemerintah Daerah Kabupaten Pasuruan sebagai unsur pelaksana urusan pemerintahan di bidang perhubungan sehingga pegawai harus dikelola dengan baik supaya dapat memberikan kontribusi yang maksimal untuk pencapaian tujuan. Karena Dinas Perhubungan Kabupaten Pasuruan sebagai organisasi publik yang memberikan pelayanan prima kepada masyarakat, diharapkan juga dapat mengimplementasikan dan meningkatkan Sistem Akuntabilitas Kinerja Instansi Pemerintah (SAKIP) dengan mempertimbangkan 5 (lima) komponen manajemen kinerja, antara 
lain: perencanaan kinerja, pengukuran kinerja, pelaporan kinerja dan evaluasi internal serta pencapaian kinerja organisasi.

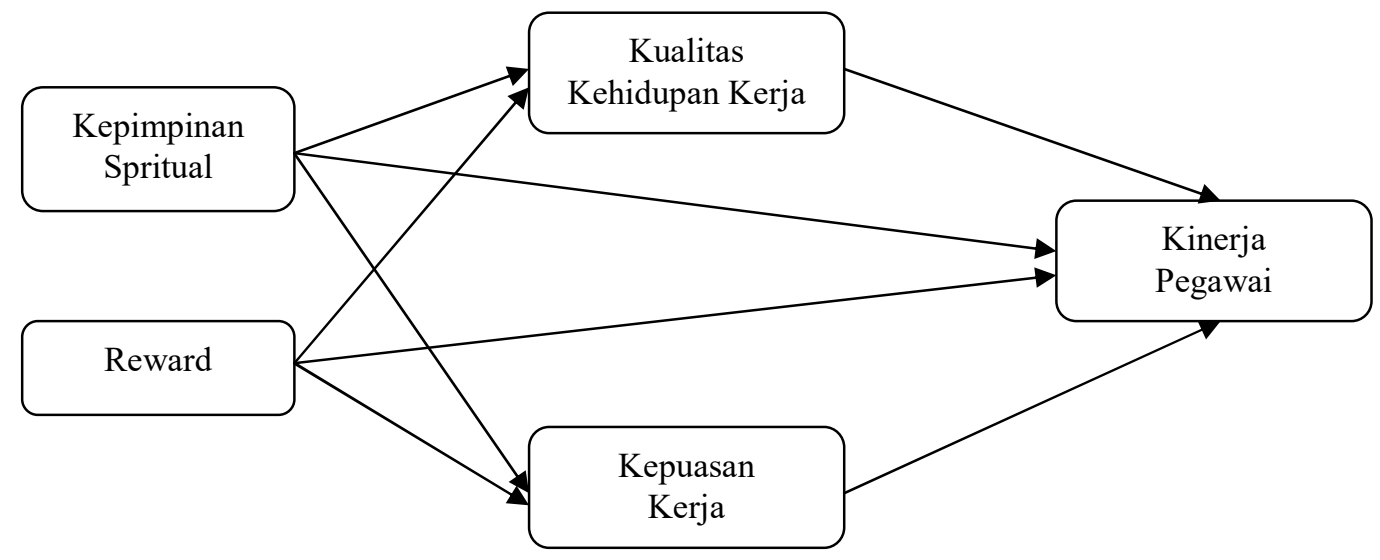

Gambar 1. Kerangka konseptual Penelitian

Gambar 1, dapat dijelaskan hipotesis pada penelitian in adalah: Hipotesis 1: Kepemimpinan spiritual berpengaruh terhadap kinerja pegawai, Hipotesis 2: Reward berpengaruh terhadap kinerja pegawai. Hipotesis 3: Kepemimpinan spiritual berpengaruh terhadap kinerja pegawai melalui kualitas kehidupan kerja sebagai variabel mediasi. Hipotesis 4: Reward berpengaruh terhadap kinerja pegawai melalui kualitas kehidupan kerja sebagai variabel mediasi. Hipotesis 5: Kepemimpinan spiritual berpengaruh terhadap kinerja pegawai melalui kepuasan kerja sebagai variabel mediasi. Hipotesis 6: Reward berpengaruh terhadap kinerja pegawai melalui kepuasan kerja sebagai variabel mediasi. Hipotesis 7: Kualitas kehidupan kerja berpengaruh positif terhadap kinerja pegawai. Hipotesis 8: Kepuasan kerja berpengaruh terhadap kinerja pegawai.

\section{METODE}

Penelitian dilaksanakan di kantor Dinas Perhubungan Kabupaten Pasuruan, yang beralamat di Jalan Raya Pakijangan Km. 17 Kecamatan Wonorejo - Kabupaten Pasuruan. Data diperoleh dengan menyebar kuesioner kepada semua karyawan Dinas Perhubungan Kabupaten Pasuruan yang merupakan Pegawai Negeri Sipil yang berjumlah 86. Pilihan jawaban pertanyaan menggunakan skala Likert dengan jawaban sangat baik dengan bobot tertinggi hingga sangat tidak baik dengan bobot terendah. Variabel dalam penelitian ini adalah kepemimpian spiritual (X1), reward (X2), kualitas kehidupan kerja (Z1) dan kepuasan kerja (Z2) sebagai variable mediasi, serta kinerja pegawai (Y). dengan pengukuran variabel pada Tabel 1.

Tabel 1. Pengukuran Variabel

\begin{tabular}{lll}
\hline \multicolumn{1}{c}{ Variabel } & \multicolumn{1}{c}{ Indikator } & \multicolumn{1}{c}{ Sumber } \\
& 1.Kejujuran dan keadilan & \\
& 2. Kepedulian dan apresiasi terhadap bawahan & \\
Kepemimpinan & 3. Berdedikasi tinggi untuk kemajuan organisasi & Rafsanjani (2017) \\
Spiritual $\left(\mathrm{X}_{1}\right)$ & $\begin{array}{l}\text { 4. Bekerja secara efektif dan efisien } \\
\text { 5.Motivasi kepada bawahan }\end{array}$ & Fry (2003) \\
& 6.Keterbukaan menerima perubahan & \\
7. Kerendahan Hati & \\
Reward $\left(\mathrm{X}_{2}\right)$ & 2.Gaji & PP 15 Tahun 2019;
\end{tabular}




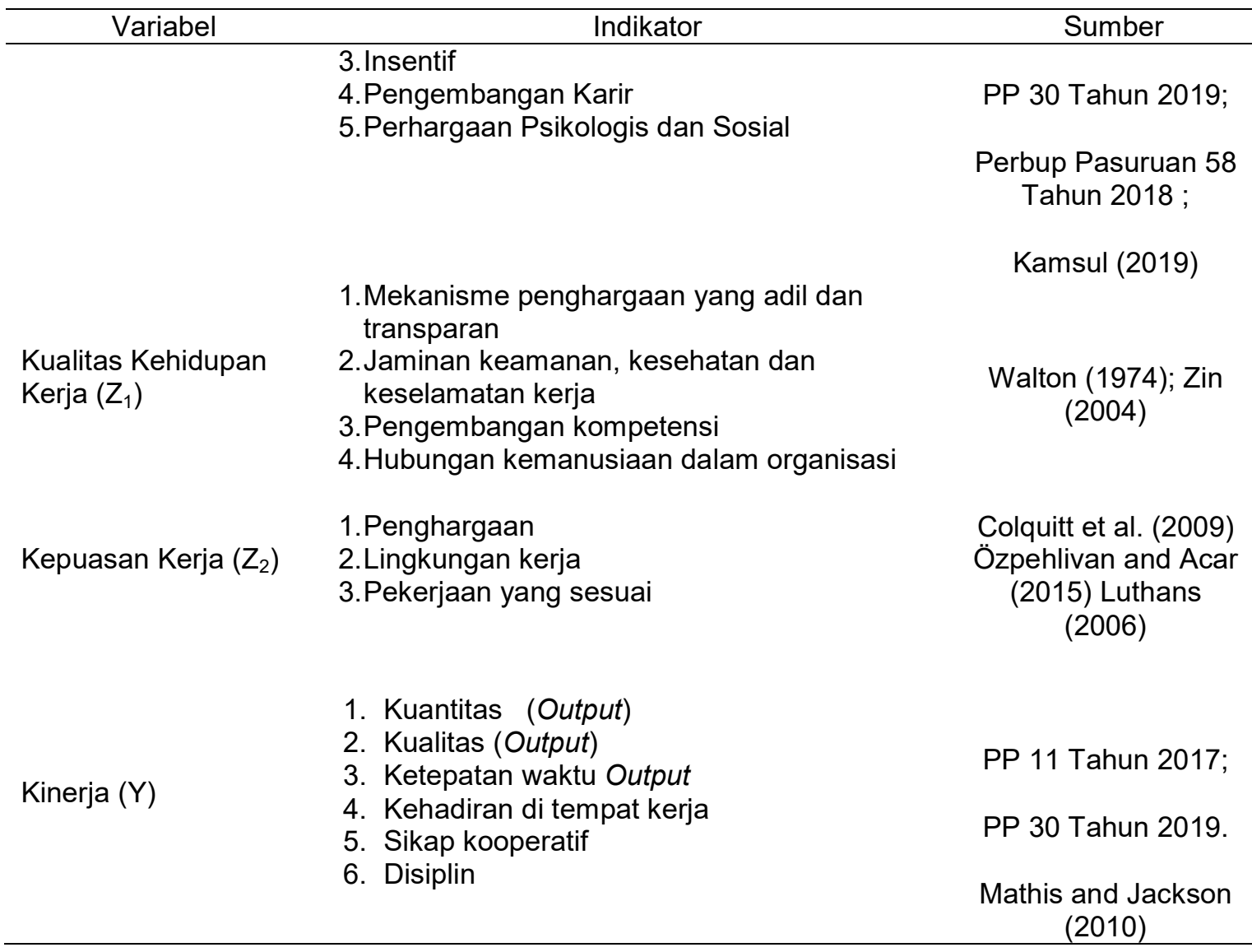

Pengujian data dilakukan dengan pendekatan SEM (Structural Equating Modeling) Partial Least Square atau SEM PLS. Tahapan analisis dalam PLS dimulai dari pengukuran model (outer model), struktur model (inner model) dan pengujian hipotesis. Penilaian outer model dimulai dengan penentuan convergent validity untuk masing-masing konstruk. Validitas konvergen sebuah konstruk dengan indikator reflektif dievaluasi dengan Average Variance Extracted (AVE). Nilai AVE dikatakan valid jika nilai outer loading lebih dari 0,5. Dalam aplikasi SmartPLS uji validitas diskriminan menggunakan nilai cross loadings dan Fornell-Larcker Criterion. Nilai cross loading yang diharapkan adalah lebih besar dari 0,7 (Ghozali, 2006). Internal Consistency Reliability digunakan untuk mengukur seberapa mampu indikator dapat mengukur konstruk latennya. Alat yang digunakan untuk menilainya adalah composite reliability dan Cronbach's alpha. Nilai composite reliability 0,6 - 0,7 dianggap memiliki reliabilitas yang baik dan nilai Cronbach's alpha yang diharapkan adalah di atas 0,7 (Sarstedt, Ringle, and Hair (2017).

Discriminant validity digunakan untuk derajat kesesuaian antara variabel atau atribut yang diukur oleh alat ukur dan konsep teoritis. Validitas diskriminan digunakan untuk mengetahui apakah suatu konstruk atau variabel laten memiliki diskriminan yang memadai yaitu dengan melihat cross loading, dengan cara membandingkan nilai pada konstruk yang dituju harus lebih besar dibandingkan dengan nilai loading dengan konstruk yang lain. Cross loading merupakan hubungan antara variabel dengan indikator yang digunakan dalam menentukan hubungannya. Hasil penelitian ini menunjukkan bahwa nilai loading dari masing-masing indikator terhadap konstruknya lebih besar daripada nilai cross loading-nya.

Composite reliability digunakan untuk mengukur nilai sesungguhnya suatu variabel laten atau konstruk. Sedangkan cronbach's alpha digunakan untuk mengukur batas bawah nilai realibilitas suatu variabel laten. 
Inner model atau model struktural. dilakukan untuk menguji hubungan antara konstruk laten. Inner model digunakan untuk melihat hubungan antar konstruk dan nilai signifkansi serta nilai $\mathrm{R}$-square $\left(\mathrm{R}^{2}\right)$ dan $\mathrm{Q}$ square. Nilai $\mathrm{R}$ square yang semakin tinggi menunjukkan model semakin fit dengan data, Nilai Q square yang semakin tinggi menunjukkan predictive relevance yang semakin tinggi, model semakin baik untuk dipergunakan dalam prediksi.

Pengujian hipotesis (resampling bootstrapping) dilakukan dengan cara uji statistik dengan menggunakan uji-t atau $\mathrm{p}$ (probabilitas). Dalam penelitian ini menggunakan tingkat kepercayaan $95 \%$ sehingga tingkat presisi atau batas ketidakakuratan $(\alpha)=5 \%=0,05$, nilai t-tabelnya adalah $1,96$.

\section{HASIL DAN PEMBAHASAN \\ Hasil}

Data dari kuesioner menunjukkan mayoritas responden adalah laki-laki sebanyak 81 orang (94,19\%). Usia responden didominasi pada rentang 31 - 45 tahun sebanyak 49 orang (56,98\%). Tingkat pendidikan responden bervariasi mulai dari lulusan SD sampai dengan S2, namun paling banyak adalah lulusan SMA yang berjumlah 42 orang $(48,84 \%)$. Sebanyak 82 responden $(95.35 \%)$ telah bekerja lebih dari 10 tahun.

Dari hasil uji dengan Partial Least Square (PLS) tahapan yang telah dilakukan adalah uji validitas dengan outor model.

\section{Evaluasi Outer Model}

Dari hasil evaluasi Outer Model diperoleh bahwa dari indikator kepemimpinan spiritual terdapat 18 pertanyaan dalam kuesioner, namun pertanyaan yang valid berjumlah 13; dari 14 indikator reward ada 8 pernyataan yang valid; sebanyak 11 indikator kualitas kehidupan kerja namun hanya 4 pertanyaan yang valid. Untuk 9 indikator kepuasan kerja, ada 6 yang valid. Terdapat 12 pertanyaan yang dari 16 indikator kinerja karyawan dinyatakan valid.

(Lihat lampiran 1. Loading factor)

Tabel 2. Nilai Reliabilitas Tiap Variabel

\begin{tabular}{lcc}
\hline \multicolumn{1}{c}{ Variabel Komposit } & Composite realibility & Keterangan \\
\hline Kepemimpinan Spiritual $\left(\mathrm{X}_{1}\right)$ & 0,955 & Reliabel \\
Reward $\left(\mathrm{X}_{2}\right)$ & 0,931 & Reliabel \\
Kualitas Kehidupan Kerja $\left(\mathrm{Z}_{1}\right)$ & 0,898 & Reliabel \\
Kepuasan $(\mathrm{Z} 2)$ & 0,913 & Reliabel \\
Kinerja Karyawan $(\mathrm{Y})$ & 0,958 & Reliabel \\
\hline
\end{tabular}

Berdasarkan Tabel 2 dapat diketahui bahwa nilai composite realibility dari setiap variabel diketahui seluruhnya telah dinyatakan reliable karena seluruh variabel memiliki nilai diatas 0,7 . Hal tersebut menandakan bahwa setiap variabel dapat dinyatakan konsisten dalam menghasilkan nilai terhadap modelnya.

\section{Evaluasi Model Struktural (Inner Model)}

Dari tabel 3 hasil $R$-square menunjukkan bahwa kepemimpinan spiritual dan reward menyumbang kualitas kehidupan kerja sebesar 60,9\% sedangkan 39,1\% disumbang oleh variabel lain. Namun Kepemimpinan spiritual dan reward menyumbang kepuasan kerja hanya sebesar $50,5 \%$ sedangkan $49.5 \%$ nya disumbang oleh faktor lain. Kinerja disumbang oleh Kepemimpinan spiritual dan Rewad sebesar 47,7\% sedangkan 52.3\% nya disumbang oleh variable lain. Berarti hal tersebut menunjukkan model semakin fit dengan data. Secara keseluruhan kepemimpinan spiritual, kualitas kehidupan kerja, reward dan kepuasan kerja 
memberi sumbangan variabel kinerja sebesar Q-square $89.8 \%$ yang berarti model tersebut mempunyai predictive relevance yang tinggi dan model semakin baik dan layak untuk dipergunakan dalam prediksi.

Tabel 3. Nilai $R$-Square dan $Q$-Square

\begin{tabular}{lc}
\hline \multicolumn{1}{c}{ Variabel } & R-Square \\
\hline $\begin{array}{l}\text { Kualitas Kehidupan } \\
\text { Kerja } \\
\text { Kepuasan Kerja }\end{array}$ & 0,609 \\
Kinerja & 0,505 \\
\hline
\end{tabular}

Q-Square $=1-(1-0.609)(1-0.505)(1-0,477)==0.898$

Tabel 4. Hasil Analisis Korelasi dan Signifikansi

\begin{tabular}{|c|c|c|c|c|}
\hline Hubungan (Korelasi) & $\mathrm{B}$ & T Stat $(1,96)$ & $P$ value & Keputusan \\
\hline $\begin{array}{l}\text { Kepemimpinan Spiritual -> } \\
\text { Kinerja }\end{array}$ & 0,233 & 1,422 & 0,156 & Tolak H1 \\
\hline $\begin{array}{l}\text { Kualitas Kehidupan Kerja -> } \\
\text { Kinerja }\end{array}$ & 0,019 & 0,128 & 0,898 & Tolak H7 \\
\hline Kepuasan Kerja -> Kinerja & 0,526 & 2,166 & 0,031 & Terima H8 \\
\hline Reward->kinerja & $-0,033$ & 0,29 & 0,772 & Tolak H2 \\
\hline $\begin{array}{l}\text { Kepemimpinan Spiritual -> } \\
\text { Kualitas Kehidupan Kerja -> } \\
\text { Kinerja }\end{array}$ & 0,013 & 0,125 & 0,901 & Tolak H3 \\
\hline $\begin{array}{l}\text { Kepemimpinan Spiritual -> } \\
\text { Kepuasan Kerja -> Kinerja }\end{array}$ & 0,188 & 1,266 & 0,206 & Tolak H5 \\
\hline $\begin{array}{l}\text { Reward -> Kualitas Kehidupan } \\
\text { Kerja -> Kinerja }\end{array}$ & 0,003 & 0,105 & 0,916 & Tolak H4 \\
\hline $\begin{array}{l}\text { Reward -> Kepuasan Kerja -> } \\
\text { Kinerja }\end{array}$ & 0,214 & 2,194 & 0,029 & Terima H6 \\
\hline
\end{tabular}

\section{Pembahasan}

Hasil pengujian yang ditunjukkan tabel 4 , menunjukkan bahwa kepemimpinan spiritual tidak mempunyai pengaruh terhadap kinerja pegawai karena $p$-value $(1,422<1,96)$ maka $\mathrm{H}_{1}$ ditolak. Hasil penelitian ini berbeda dengan penelitian terdahulu yang dikemukakan oleh Pio, Nimran, Alhabsji, and Hamid (2015), Pio and Tampi (2018), Roni (2019) yang menegaskan adanya pengaruh kepemimpinan spiritual terhadap kinerja.

Perbedaan hasil penelitian dapat disebabkan karena terdapat perbedaan perilaku kepemimpinan dan perbedaan karakteristik pada suatu organisasi. Hal ini sesuai dengan penelitian Kakiay (2017) yang menyimpulkan bahwa kepemimpinan spiritual tidak mendorong peningkatan kinerja. Menurutnya, hal tersebut bisa disebabkan masa kepemimpinan yang terlalu lama, dan sudah menjadi tugas dan tanggung jawab yang diembankan yayasan kepada organisasi, Dengan demikian dapat diartikan bahwa kepemimpinan spiritual tidak dapat secara langsung meningkatkan kualitas kerja dan kinerja karyawan sesuai dengan harapan organisasi. Hasil korelasi dan signifikasi variabel ditampilkan dalam tabel 4.

Data pada tabel 4 menunjukkan hasil bahwa reward tidak berpengaruh terhadap kinerja pegawai (t-stat $0.290<1.96)$, maka $\mathrm{H}_{2}$ ditolak. Hasil penelitian ini sejalan Roni (2019) yang menyatakan bahwa reward tidak berpengaruh terhadap kinerja karyawan. Namun berkebalikan dengan Haryanto (2017), Praptiestrini and Rohwiyati (2018) yang membuktikan bahwa pemberian reward dapat meningkatkan semangat dan motivasi kerja pegawai sehingga meningkatkan kinerja di dalam melaksanakan tugas pokok dan fungsinya memberikan pelayanan 
publik sesuai dengan bidang kerjanya masing-masing. Perbedaan hasil penelitian ini karena selama ini pemberian reward kepada pegawai Dinas Perhubungan hanya berupa plakat, sertifikat dan piagam sehingga dirasakan pegawai belum menunjukkan keadilan dan belum sesuai dengan tujuan untuk meningkatkan semangat dalam upaya peningkatan kinerja pegawai. Kondisi tersebut didukung dengan hasil dari jawaban kuesioner responden tentang variabel reward, bahwasanya masih ditemukan frekuensi jawaban kurang setuju yang cukup tinggi (lebih dari $10 \%$ ) terkait gaji, tunjangan, insentif maupun penghargaan psikologis dan sosial yang diterima pegawai. Selain itu, asumsi pegawai tentang adanya kenaikan pangkat secara otomatis akan tetap berjalan, kecuali jika terdapat indisipliner.

Berdasarkan hasil penelitian didapatkan hasil bahwa kepemimpian spiritual terhadap kinerja yang dimediasi oleh kualitas kehidupan kerja memiliki hubungan positif $(0,013)$ namun tidak signifikan (t-statistik $0,125<1,96$ ), maka $\mathrm{H}_{3}$ ditolak. Hasil penelitian ini berbeda dengan penelitian Raharjani (2018) yang dilakukan pada karyawan Bank Mandiri Semarang yang menyimpulkan bahwa kualitas kehidupan kerja mampu menjadi mediator terhadap kinerja karyawan. Perbedaan hasil ini penelitian ini dimungkinkan karena adanya perbedaan karakteristik organisasi dan persepsi pimpinan organisasi dalam penciptaan kualitas kehidupan kerja yang baik dimana organisasi dalam penelitian ini berada pada organisasi pelayanan publik dan merupakan organisasi pemerintahan. Masa kepemimpinan yang singkat dapat menjadi penghambat kinerja karyawan karena dianggap masa internalisasi nilai-nilai kepemimpinan spiritual terlalu pendek (Ivancevich, Konopaske, \& Matteson, 1985)

Pengaruh reward terhadap kinerja yang dimediasi oleh kualitas kehidupan kerja memilik hubungan positif $(0,003)$ namun tidak signifikan (t-statistik $0,105<1,96)$, maka $\mathrm{H}_{4}$ ditolak. Hasil penelitian ini tidak sejalan dengan penelitian Husnawati (2006) yang menyatakan bahwa kualitas kehidupan kerja mampu untuk meningkatkan peran serta dan sumbangsih para pegawai atau karyawan terhadap organisasi. Perbedaan hasil penelitian ini dikarenakan kualitas kehidupan karyawan yang diciptakan oleh institusi saat ini hanya mampu memberikan rasa aman dan nyaman bagi karyawan, tetapi tidak bisa meningkatkan motivasi, kepuasan dan keyakinan diri karyawan dan hal tersebut tidak mampu mendorong karyawan untuk memberikan kinerja yang optimal bagi organisasi. Ditambahkan lagi bahwa reward yang diberikan kepada pegawai hanya berupa plakat, sertifikat dan piagam.

Berdasarkan hasil penelitian didapatkan hasil bahwa kepemimpian spiritual terhadap kinerja yang dimediasi oleh kepuasan kerja memiliki hubungan positif $(0,188)$ namun tidak signifikan (t-statistik $1,266<1,96$ ), maka $\mathrm{H}_{5}$ ditolak. Hasil penelitian ini berbeda dengan yang dilakukan Cahyono (2019) yang menyatakan bahwa pengaruh tidak langsung kepemimpinan terhadap kinerja karyawan yang dimediasi kepuasan kerja adalah signifikan. Dari hasil penelitian ini memberikan makna kepemimpinan spiritual seorang pemimpin tidak memberi dampak terhadap kinerja kerja karyawan meskipun dimediasi oleh kepuasan kerja. Meskipun pemimpin memiliki kemampuan untuk memotivasi para karyawan untuk mencapai tujuan organisasi namun tidak meningkatkan kepuasan dan kinerja, berarti ada faktor lain yang mempengarui kepuasan dan kinerja karyawan. Kepemimpinan yang baik akan berpengaruh terhadap peningkatan kepuasan kerja namun belum tentu juga akan diiringi dengan peningkatan kinerja pegawai. Hal ini mendukung hasil Hartono, Hamid, and Yusuf (2016) yang menyatakan bahwa pengaruh kepemimpinan terhadap kinerja karyawan yang dimediasi oleh kepuasan kerja berpengaruh positif tetapi tidak signifikan. Karena kepuasan lebih banyak dirasakan dari reward yang diberikan dari pada hanya adanya kepemimpinan spiritual. Hal ini didukung dari diterimanya Hipotesis 6 yang menjawab bahwa reward mempengaruhi kepuasan kerja (Ajila \& Abiola, 2004)

Berdasarkan hasil penelitian didapatkan hasil bahwa pengaruh reward terhadap kinerja yang dimediasi oleh kepuasan kerja memiliki hubungan positif $(0,214)$ dan signifikan (t-statistik 2,194 $>1,96)$, maka $\mathrm{H}_{6}$ diterima. Hasil penelitian ini juga mendukung penelitian sebelumnya yang 
dilakukan Praptiestrini \& Rohwiyati (2018); Ajila and Abiola (2004). Hasil temuan mereka menyatakan bahwa peningkatan kinerja karyawan dapat diwujudkan apabila karyawan mendapatkan kepuasan dalam bekerja dan kepuasan kerja dapat diwujudkan melalui pemberian reward yang adil, layak dan memiliki nilai misalnya ekstrinsik reward untuk memuaskan kebutuhan karyawan tersebut.

Hasil pengujian yang ditunjukkan tabel 4 , didapat bahwa kepemimpinan spiritual memiliki hubungan positif $(0,019)$ dan tidak signifkan $(0,128<1,96)$ terhadap kinerja pegawai maka $\mathrm{H}_{7}$ ditolak. Hasil temuan dengan penelitian ini berbeda dengan yang dikemukakan Hasmalawati and Hasanati (2017) yang menyatakan bahwa kualitas kehidupan kerja berpengaruh secara signifikan terhadap kinerja karyawan yang selanjutnya dapat membuat karyawan lebih produktif dalam meningkatkan pelayanan kepada masyarakat. Namun hasil penelitian ini sesuai dengan penelitian Rubel and Kee (2014), Zohurul and Siengthai (2009) yang menjelaskan bahwa Quality Work For Life tidak mempengaruhi kinerja. Hal ini juga didukung oleh Kusnoto and Sitorus (2016) yang menjelaskan bahwa meskipun lingkungan kerja baik dan memenuhi kebutuhan karyawan namun tidak langsung dapat meningkatkan kinerja karyawan secara signifikan karena kualitas kehidupan kerja perusahaan hanya akan memberikan rasa aman dan nyaman bagi karyawan saja. Jika tanpa didasari motivasi dan keyakinan diri karyawan, maka kondisi tersebut tidak akan mendorong karyawan bekerja maksimal untuk mencapai kinerja yang tinggi. Hal ini dimungkinkan karena adanya perbedaan kebijakan dan persepsi pimpinan atau organisasi dalam aspek kualitas kehidupan kerja untuk peningkatan produktivitas dan kinerja karyawan.

Hasil pengujian yang ditunjukkan tabel 4, didapat bahwa kepuasan kerja memiliki hubungan positif $(0,526)$ dan signifkan $(2,166>1,96)$ terhadap kinerja pegawai maka $\mathrm{H}_{8}$ diterima. Hasil dalam penelitian ini sejalan dengan hasil penelitian Bobo (2019), Jalal and Zaheer (2017) yang menegaskan bahwa kepuasan kerja berpengaruh signifikan terhadap kinerja. Hal ini dimungkinkan karena sudah terpenuhinya kepuasan kerja karyawan dalam bentuk gaji yang diterima, lingkungan kerja yang kondusif, pekerjaan yang sesuai dengan bidangnya. Ditambahkan oleh Kumorojati and Endratno (2014) yang menjelaskan bahwa pengaruh kepuasan kerja terhadap kinerja juga terkait dengan perilaku karyawan yang spesifik atau dipersepsikan bahwa produktivitas dan kinerja yang meningkat disebabkan adanya kepuasan kerja apabila karyawan mempersepsikan apa yang telah dicapai oleh organisasi sesuai dengan apa yang karyawan terima (gaji/ upah) yaitu adil dan wajar. Jadi idealnya jika karyawan bahagia dan puas, maka mereka akan memiliki emosi yang baik dan bekerja lebih produktif (Jalagat, 2016).

\section{SIMPULAN}

Hanya ada dua hipotesis yang diterima yaitu $\mathrm{H}_{8}$ yang menyatakan bahwa kepuasan kerja berpengaruh terhadap kinerja pegawai, dan $\mathrm{H}_{6}$ yang membuktikan bahwa Reward secara tidak langsung mempengaruhi kinerja, namun perlu dimediasi oleh kepuasan kerja agar berpengaruh positif dan signifikan terhadap kinerja pegawai. Hipotesis yang lain yaitu $\mathrm{H}_{1}, \mathrm{H}_{2}, \mathrm{H}_{3}, \mathrm{H}_{4}, \mathrm{H}_{5}$ dan $\mathrm{H}_{7}$ ditolak. Dengan demikian hanya pemberian reward yang mampu memberikan kepuasan kerja sehingga dapat meningkatkan kinerja karyawan, sedangkan kepemimpinan spiritual dan kualitas kehidupan kerja tidak berpengaruh terhadap kinerja pegawai baik secara langsung maupun ketika dimediasi oleh kepuasan kerja. Berdasarkan hasil penelitian, kepuasan kerja secara parsial maupun sebagai variabel mediasi berpengaruh secara signifikan terhadap kinerja pegawai Dinas Perhubungan Kabupaten Pasuruan dengan demikian organisasi sebaiknya berfokus pada peningkatan kepuasan kerja pegawai melalui peran spiritualitas pemimpin yang lebih baik melalui komunikasi yang efektif, pemberian motivasi dan kepedulian terhadap bawahan agar berprestasi, penciptaan kualitas kehidupan kerja yang harmonis, serta kedepannya 
di dalam program organisasi lebih memperhatikan kebutuhan, kesejahteraan dan hak pegawai melalui pemberian reward yang adil berdasarkan prestasi dan hasil kerja pegawai.

\section{REFERENSI}

Ahmad, H., Ahmad, K., \& Shah, I. A. (2010). Relationship between Job Satisfaction, Job Performance Attitude towards Work and Organizational Commitment. European Journal of Social Sciences, 18(2).

Ajila, C., \& Abiola, A. (2004). Influence of Rewards on Workers Performance in an Organization. Journal of Social Sciences, 8(1), 7-12.

Bobo, J. (2019). Pengaruh Kepemimpinan Transformsional, Motivasi Kerja dan Kepuasan Kerja terhadap Kinerja Karyawan dengan Komitmen Organisasional Sebagai Variabel Mediasi. (Master), Universitas Sanata Dharma, Yogyakarta.

Chanana, M., \& Gupta, S. (2016). Quality of Work Life and Its Impact on Job Performance: A Study of S.B.I \& HDFC Banking Professionals. International Research Journal of Management, IT \& Social Sciences, 3. doi: 10.21744/irjmis.v3i5.12

Colquitt, J. A., Lepine, J. A., \& Wesson, M. J. (2009). Organizational behavior: Improving performance and commitment in the workplace. New York: McGraw-Hill Irwin.

Cross, O., \& Daniel, C. (2020). Analysis of Quality Work Life on Employees Performance. 6065.

Delamotte, Y., \& Walker, K. F. (1976). Humanization of Work and the Quality of Working Life - Trends and Issues. International Journal of Sociology, 6(1), 8-40. doi: 10.1080/15579336.1976.11769634

Fadhil, A., \& Mayowan, Y. (2018). Pengaruh Motivasi Kerja Dan Kepuasan Kerja Terhadap Kinerja Karyawan Ajb Bumiputera. Jurnal Administrasi Bisnis (JAB)|, 54(1).

Fry, L. W. (2003). Toward a theory of spiritual leadership. The Leadership Quarterly, 14, 693727.

Ghasemizad, A. (2013). Study of the Relationship between Teachers and Principals' Spiritual Leadership, Quality of Work Life, Job Satisfaction and Productivity. American Journal of Scientific Research.

Ghasemizad, A., Zadeh, M. A., \& Bagheri, S. (2012). A Study of the Relationship between Teachers and Principals' Spiritual Leadership, Quality of Work Life, Job Satisfaction and Productivity. American Journal of Scientific Research, 49, 11-20.

Ghozali, I. (2006). Structural Equation Model Metode Alternatif dengan Partial Least Square. Semarang: Badan Penerbit Universitas Diponegoro.

Hartono. (2018). Pengaruh Kepemimpinan Situasional Terhadap Kinerja Karyawan Melalui Kepuasan Kerja Dan Organizational Citizenship Behavior Sebagai Variabel Intervening (Studi Kasus Pada Kantor PT. Nindya Karya Cabang Makassar). (Master), Universitas Hasanudin Makasar.

Hartono, Hamid, N., \& Yusuf, R. M. (2016). Pengaruh Kepemimpinan Situasional Terhadap Kinerja Karyawan Melalui Kepuasan Kerja Dan Organizational Citizenship Behavior Sebagai Variabel Intervening. Hasanuddin Journal of Applied Business and Entrepreneurship, 1(2).

Haryanto, D. (2017). Pengaruh Gaya Kepemimpinan, Kompensasi Dan Komitmen Organisasi Terhadap Kinerja Karyawan Cv. Indyferyto Group Yogyakarta. SMART - Study \& Management Reseach, X(3), 55-65.

Hasmalawati, N., \& Hasanati, N. (2017). Pengaruh Kualitas Kehidupan Kerja dan Motivasi Kerja Terhadap Kinerja Karyawan. MEDIAPSI, Vol. 3(2), 1-9.

Henis Fiqih, A., Mochammad Al, M., \& Tri Wulida, A. (2016). Pengaruh Locus of Control Terhadap Kepuasan Kerja Dan Kinerja (Studi Pada Karyawan Perusahaan Daerah Air 
Minum (Pdam) Kota Malang). Jurnal Administrasi Bisnis S1 Universitas Brawijaya, 35(1), 68-77.

Ivancevich, J., Konopaske, R., \& Matteson, M. (1985). Organizational behavior and management.

Jalagat, R. (2016). Job Performance, Job Satisfaction, and Motivation: A Critical Review of their Relationship. International Journal of Advances in Management and Economics, 5(6), $36-42$.

Jalal, R. N.-U.-D., \& Zaheer, M. A. (2017). Does Job Satisfaction Mediate the Relationship of Workload, Remuneration and Psychological Reward with Job Performance? International Journal of Academic Research in Business and Social Sciences, 7(9).

Kakiay, A. N. (2017). Pengaruh Kepemimpinan Spiritual Dan Kepuasan Kerja Terhadap Kinerja Guru. Jurnal Psikologi, 10(2).

Kamsul. (2019). Implementasi Pemberian Penghargaan Berdasarkan Prestasi Penilaian Kerja Pegawai Negeri Sipil Dalam Upaya Meningkatkan Kinerja Pegawai di Lingkugan Pemerintah Kabupaten Bangka Tengah. (Master), Universitas Terbuka, Jakarta.

Kumorojati, D., \& Endratno, H. (2014). Pengaruh Karakteristik Individu, Karakteristik Pekerjaan dan Budaya Organisasi Terhadap Kepuasan Kerja Karyawan yang Dimediasi Motivasi Kerja. Jurnal Bisnis dan Manajemen, 2(1), 58-72.

Kusnoto. (2011). Pengaruh Gaya Kepemimpinan Dan Reward Terhadap Kinerja Guru Di Madrasah Aliyah Asy-Syafi 'iyah Margasari Kabupaten Tegal. (Master), Institut Agama Islam Negeri (Iain) Syekh Nurjati Cirebon.

Kusnoto, \& Sitorus, T. (2016). Kualitas Kehidupan Kerja, Self Efficacy, Dan Kinerja Karyawan: Efek Mediasi Motivasi Kerja (Study Pada Pt Bank Bri Cabang Bsd). Jurnal Manajemen, 13(2), 198-224.

Luthans, F. (2006). Perilaku Organisasi. Yogyakarta: Andi.

Mardiasmo. (2009). Akuntansi Sektor Publik. Yogyakarta: Andi Offset.

Mathis, R. L., \& Jackson, J. H. (2010). Human Resource Management (13 ed.). Ohio: SouthWestern College Publishing.

Meyrina, S. A. (2017). Pelaksanaan Reward Dan Punishment Terhadap Kinerja Pegawai Di Lingkungan Kementerian Hukum Dan Ham. Jurnal Ilmiah Kebijakan Hukum, 11(2), 139-157.

Mohd Yusuf, B. N. (2013). The Effect of Rewards towards Job Performance among ChemicalBased Employees. International Journal of Business and Management Tomorrow, 2, 111.

Muslichah, \& Asrori, S. (2018). The Effect of Transformational Leadership Style on Job Satisfaction with Trust-In-Leader as Intervening Variable. Journal of Innovation in Business and Economics, 2(2), 61-70.

Özpehlivan, M., \& Acar, A. Z. (2015). Assessment of a Multidimensional Job Satisfaction Instrument. Procedia - Social and Behavioral Sciences, 210, 283-290. doi: 10.1016/j.sbspro.2015.11.368

Pio, R. J., Nimran, U., Alhabsji, T., \& Hamid, D. (2015). Pengaruh Kepemimpinan Spiritual Terhadap Perilaku Etis, Kualitas Kehidupan Kerja, Kepuasan Kerja, Komitmen Organisasional dan Kinerja Karyawan [Influence of Spiritual Leadership on Ethical Behavior, Quality of Work Life, Job Satisfaction, Organizational Commitment, and Employee Performance]. 2015, 10(1), 39. doi: 10.19166/derema.v10i1.173

Pio, R. J., \& Tampi, J. R. E. (2018). The influence of spiritual leadership on quality of work life, job satisfaction and organizational citizenship behavior. International Journal of Law and Management, 60(2), 757-767. doi: 10.1108/IJLMA-03-2017-0028 
Praptiestrini, \& Rohwiyati. (2018). Pengaruh Reward Terhadap Kinerja Karyawan: Peran Kepuasan Kerja Dan Komitmen Organisasional Sebagai Pemediasi (Survei Pada Karyawan Sales Force Otomotif Di Wilayah Surakarta). Jurnal Ekonomi Dan Kewirausahaan, 18(4).

Rafsanjani, H. (2017). Kepemimpinan spiritual. Jurnal Masharif al-Syariah: Jurnal Ekonomi dan Perbankan Syariah, 2(1).

Raharjani, G. W. (2018). Peningkatan Kepuasan Kerja, Komitmen Organisasi Dan Kualitas Kehidupan Kerja Berbasis Keadilan Organisasi Terhadap Kinerja Sumber Daya Manusia (Studi pada PT. Bank Mandiri (Persero) Kantor Cabang Semarang Mpu Tantular). (Sarjana), Universitas Islam Sultan Agung, Semarang.

Reave, L. (2005). Spiritual values and practices related to leadership effectiveness. The Leadership Quarterly, 16, 655-687.

Rida, M. A. (2018). Pengaruh Kepemimpinan Dan Etos Kerja Islami Terhadap Komitmen Dan Kinerja Karyawan Rsu Pku Muhammadiyah/Aisyiyah Di Jawa Tengah. (Master), Universitas Muhammadiyah Yogyakarta, Yogyakarta.

Roni, M. (2019). Pengaruh Religiusitas, Kepemimpinan, Etos Kerja,Kepuasan Kerja Dan Kompensasi Terhadap Kinerja Karyawan Dengan Motivasi Sebagai Variabel Intervening (Studi Pada Kspps Bmt Nurul Ummah Ngasem Bojonegoro Jawa Timur). (Pasca Sarjana), Universitas Islam Negeri Sunan Ampel, Surabaya.

Rubel, M. R. B., \& Kee, D. M. H. (2014). Quality of Work Life and Employee Performance: Antecedent and Outcome of Job Satisfaction in Partial Least Square (PLS). World Applied Sciences Journal, 31(4), 456-467.

Sarstedt, M., Ringle, C., \& Hair, J. (2017). Partial Least Squares Structural Equation Modeling.

Sureskiarti, E. (2017). Pengaruh Penerapan Spiritual Leadership Terhadap Kinerja Perawat Dalam Melaksanakan Asuhan Keperawatan Di Rumah Sakit Ibu Dan Anak Aisiyah Samarinda. JURNAL ILMU KESEHATAN, 5(1), 27-33.

Walton, R. E. (1974). Prospects and problems. In Measuring the quality of Working Life. Paper presented at the A Symposium on Social Indicators of Working Life, Ottawa.

Wang, M., Guo, T., Ni, Y., Shang, S., \& Tang, Z. (2019). The Effect of Spiritual Leadership on Employee Effectiveness: An Intrinsic Motivation Perspective. Frontiers in Psychology, 9(2627). doi: 10.3389/fpsyg.2018.02627

Yvonne, W., Rahman, R. H. A., \& Long, C. S. (2014). Employee Job Satisfaction and Job Performance: A Case Study in a Franchised Retail-Chain Organization. Research Journal of Applied Sciences, Engineering and Technology, 8(17), 1875-1883.

Zin, R. M. (2004). Perception of Professional Engineers toward Quality of Worklife and Organizational Commitment: A Case Study. 2004, 6(3), 12. doi: 10.22146/gamaijb.5553

Zohurul, I., \& Siengthai, S. (2009). Quality of work life and organizational performance: Empirical evidence from Dhaka Export Processing Zone.

Peraturan Bupati Pasuruan Nomor 55 Tahun 2016 Kedudukan, Susunan Organisasi, Tugas dan Fungsi Serta Tata Kerja Dinas Perhubungan Kabupaten Pasuruan. 14 Desember 2016. Lembaran Daerah Kabupaten Pasuruan Tahun 2016 Nomor 55. Pasuruan.

Peraturan Daerah Kabupaten Pasuruan Nomor 16 Tahun 2016 Pembentukan dan Susunan Perangkat Daerah. 4 Oktober 2016. Lembaran Daerah Kabupaten Pasuruan Tahun 2016 Nomor 10. Pasuruan.

Peraturan Pemerintah Republik Indonesia Nomor 30 Tahun 2019 Penilaian Kinerja Pegawai Negeri Sipil. 29 April 2019. Lembaran Negara Republik Indonesia Tahun 2019 Nomor 77. Jakarta. 
Peraturan Pemerintah Republik Indonesia Nomor 35 tahun 2010 tentang Pelaksanaan Undangundang Nomor 20 Tahun 2009 Gelar, Tanda Jasa dan Tanda Kehormatan. 12 Februari 2010. Lembaran Negara Republik Indonesia Tahun 2010 Nomor 43. Jakarta.

Undang-undang Republik Indonesia Nomor 5 Tahun 2014 Aparatur Sipil Negara. 15 Januari 2014. Lembaran Negara Republik Indonesia Tahun 2014 Nomor 6. Jakarta.

Undang-undang Nomor 23 Tahun 2014 Pemerintahan Daerah. 2 Oktober 2014. Lembaran Negara Republik Indonesia Tahun 2014 Nomor 244. Jakarta.

Undang-undang Nomor 13 Tahun 2003 Ketenagakerjaan. 25 Maret 2003. Lembaran Negara Republik Indonesia Tahun 2003 Nomor 39. Jakarta.

United National Development Progamme. (2002). Human Development Report (Deepening Democracy in a Fragmented World). New Yor: Oxford University Press, Inc. 